\title{
Foreword for the special section on wind and solar energy: uncovering and accommodating their impacts on electricity markets
}

\author{
Pinson, Pierre; O'Malley, Mark
}

Published in:

IEEE Transactions on Power Systems

Link to article, DOI:

10.1109/TPWRS.2015.2414722

Publication date:

2015

Document Version

Publisher's PDF, also known as Version of record

Link back to DTU Orbit

Citation (APA):

Pinson, P., \& O'Malley, M. (2015). Foreword for the special section on wind and solar energy: uncovering and accommodating their impacts on electricity markets. IEEE Transactions on Power Systems, 30(3), 1557-1559. https://doi.org/10.1109/TPWRS.2015.2414722

\section{General rights}

Copyright and moral rights for the publications made accessible in the public portal are retained by the authors and/or other copyright owners and it is a condition of accessing publications that users recognise and abide by the legal requirements associated with these rights.

- Users may download and print one copy of any publication from the public portal for the purpose of private study or research.

- You may not further distribute the material or use it for any profit-making activity or commercial gain

- You may freely distribute the URL identifying the publication in the public portal 


\section{Foreword for the Special Section on Wind and Solar Energy: Uncovering and Accommodating Their Impacts on Electricity Markets}

\section{ConteXt AND Motivations}

$\mathbf{E}$ LECTRICITY network and markets were designed based on a long history of dealing with various forms of dispatchable generation, as well as a fairly predictable inelastic electricity consumption pattern, in a centralized top-down manner. Little uncertainty was involved on both generation and demand sides, hence allowing for a design of electricity markets accounting for the necessity of a forward optimal allocation, with a real-time mechanism supporting actual power system operation. An excellent overview of electricity markets in the USA was given in [1], complemented by a discussion of their future evolution. This paper is a perfect example of the rate at which the context evolved over the last decade since, when published in 2005, this article did not mention the potential role of renewables in evolving electricity markets. For comparison, the discussion on the potential impact of wind energy on electricity markets was already initiated in Denmark [2], where instantaneous wind penetration had reached $100 \%$.

Owing to the ever-increasing penetration of variable renewable energy (wind and solar photovoltaic) generation in power systems, the electricity market paradigms of today are being challenged. Their zero marginal cost, combined with their inherent variability and limited level of predictability, has led to a growing consensus such that (potentially radical) changes in electricity market design and operations are required; see [3] for instance. Besides, the inherent differences in the way these markets were originally designed, for instance in Europe and in the USA [4], may clearly influence the necessary developments for optimal integration of distributed energy resources, e.g., depending upon grid considerations and operational practice. A review of recent evolutions of electricity markets towards better integration of renewables (as well as demand response) can be found in [5]. On the academic side, a number of scholars are investing substantial efforts in developing and benchmarking new proposals for the integration of renewables in electricity markets, while also bringing these ideas to students and young researchers for them to eventually contribute to tackling these challenges ahead of us. For a comprehensive overview, the reader is referred to [6].

For the case of some European countries with substantial renewable energy penetration already, e.g., Germany and Denmark, negative effects on power system operation as well as on investment in the capacities necessary to insure acceptable levels of power system reliability are being observed. Such a context motivated the proposal for this special section of the

Digital Object Identifier 10.1109/TPWRS.2015.2414722
IEEE TRANSACtions on Power Systems. Our aim is to give particular focus on some of the areas of investigation that may allow to 1) uncover the impact of renewables on electricity market (e.g., on market-clearing outcomes, need for ancillary services, and investment), and to 2) propose methodological innovations, being theoretically sound and of practical relevance, in order to accommodate substantial shares of renewables in power systems. These topics appear to be timely, since a total of 72 high-quality abstracts were submitted for consideration. Out of this large number of abstracts, 9 papers were eventually accepted, covering a selection of the topics originally proposed for this special section. There certainly exist many more timely and relevant problems related to renewables in electricity markets, and we hope that this selection of papers will provide inspiration for future work.

\section{Contributions From This Special Section}

Firstly, it is of utmost importance to uncover, analyze, and appraise the effect of renewable energy generation on market dynamics, from both theoretical and empirical perspectives. This is what is done by Hildmann et al. [7] here, with focus on the EPEX market over Germany and Austria, also accounting for the additional contribution of regulatory support to renewables on the market. With the increased availability of market data, such analyses and support to the discussion on future electricity markets ought to become more and more common.

One could argue that the inherent uncertainty in renewable energy generation should be acknowledged in the design of electricity markets. While the optimal coordination of day-ahead and balancing markets in a stochastic programming framework (or the likes) yields a number of practical challenges, Zhao et al. [8] put forward an interesting alternative setup where market participants with a share of renewable energy generation in their portfolio could trade both firm and risky power contracts. They consequently coin the term of "risky power market" to refer to this market mechanism allowing to exchange uncertain power output. This concept is analyzed from both theoretical and practical points of view, with an example application inspired by the test case of the Pennsylvania-New Jersey-Maryland (PJM) interconnection.

Similarly, focusing on the clearing and subsequent commitment and dispatch orders for markets substantially penetrated by renewable energy generation, Zhang et al. [9] describe and analyze an alternative to exciting stochastic programming and risk-limiting approaches to the coordination of day-ahead and balancing stages. Clear advantages of that proposal include the convexity of the optimization problem to be solved, as well as 
the reasonable computational costs necessary to obtain the commitment and dispatch solutions. This could hence make it a relevant candidate for practical implementation.

Another promising approach to revisiting market-based operation of power system would consist in revisiting the ways reserves, allowing to subsequently cope with unforeseen events, are defined. The proposal of Lyon et al. [10] is to consider dynamic reserve policies following a zonal model, where the reserve zones are determined prior to clear the day-ahead market. The implications in terms of costs and payments, system reliability, as well as market transparency, are subsequently analyzed.

More generally, considering the way electricity markets may be impacted by renewables, De Sisternes et al. [11] describe an elegant market modeling setup allowing to analyze the impact of bidding rules and regulatory uncertainty on revenues and consumer costs, even for complex market setups in terms of bidding rules. Their proposal framework then allows them to look at transitory regimes where market setups and generation mix are not adapted to the share of renewables in the system, which is likely to be the case for nearly all electricity markets worldwide.

For electricity markets where new products are thought of and designed in order to better accommodate the variability of renewable power generation, while rewarding units providing such services, limited knowledge exists on the potential strategic behavior of these service providers, especially in a network-constrained setup. In that vein, Moiseeva et al. [12] propose a comprehensive game-theoretical framework permitting to analyze strategic behavior of units offering ramping capability.

Still focusing on strategic behavior, but on the side of renewable energy producers, it is also of utmost importance to analyze and understand how their potential forming of coalitions could bring positive and/or negative effects to electricity markets. Zhang et al. [13] look at this problem of coalition formation under uncertainty in power generation (and resulting penalties induced by resulting balancing needs), proposing a formulation permitting to derive interesting conclusions on the impact of coalition formation. Their analysis supports the idea that beneficial coalition of renewable energy producers would indeed exist, having the effect of reducing uncertainty while not necessarily yielding market power.

Besides market operation and gaming aspects, potential strategies for transmission and generation expansion planning are significantly affected by the increased penetration of renewables. Studying these problems require the formulation of complex optimization problems reflecting the game-theoretical aspects involved. The proposal of Maurovich-Horvat et al. [14] is a representative example of employing hierarchical optimization to compare different setups for transmission and wind investment in a deregulated environment. In parallel, Levin and Botterud [15] describe a mixed-integer program for generation expansion, allowing to analyze the impact of increased deployment of wind power generating capacity on revenues of conventional generators. This framework is subsequently employed to discuss profitability for thermal and peaking units based on a simplified case-study for Illinois.

\section{Closing}

Finally, we must acknowledge the efforts of the authors and reviewers who have worked hard on improving the contents of the various papers, in order to sharpen the original ideas proposed, and to optimize their presentation. Prof. Antonio Conejo, Editor-in-Chief for the journal, ought to be acknowledged for his supportand guidanceall along the process of preparing this special section, from discussing the original proposal to its finalization.

\author{
PierRe Pinson, Guest Editor \\ Centre for Electric Power and Energy \\ Technical University of Denmark \\ Kgs. Lyngby, Denmark \\ ppin@dtu.dk
}

MARK O'MALLEY, Guest Editor
Electricity Research Centre
University College Dublin
Dublin, Ireland
mark.omalley@ucd.ie

\section{REFERENCES}

[1] R. Baldick, U. Helman, B. F. Hobbs, and R. P. O'Neill, "Design of efficient generation markets," Proc. IEEE, vol. 93, no. 11, pp. 1998-2012, Nov. 2005.

[2] P. E. Morthorst, "Wind power and the conditions at a liberalized power market," Wind Energy, vol. 6, no. 3, pp. 297-308, Jul./Sep. 2003.

[3] C. Hiroux and M. Saguan, "Large-scale wind power in European electricity markets: Time for revisiting support schemes and market designs?," Energy Policy, vol. 38, no. 7, pp. 3135-3145, Jul. 2010.

[4] K. Imran and I. Kockar, "A technical comparison of wholesale electricity markets in North America and Europe," Elect. Power Syst. Res., vol. 108, pp. 59-67, Mar. 2014.

[5] Q. Wang, C. Zhang, Y. Ding, G. Xydis, J. Wang, and J. Østergaard, "Review of real-time electricity markets for integrating distributed energy resources and demand response," Appl. Energy, vol. 138, pp. 695-706, Jan. 2015.

[6] J. M. Morales, A. Conejo, H. Madsen, P. Pinson, and M. Zugno, Integrating Renewables in Electricity Markets: Operational Problems, ser. Int. Series in Operations Research and Management Science. New York, NY, USA: Springer, 2014.

[7] M. Hildmann, A. Ulbig, and G. Andersson, "Empirical analysis of the merit-order effect and the missing money problem in power markets with high RES shares," IEEE Trans. Power Syst., vol. 30, no. 3, pp. 1560-1570, May 2015.

[8] Y. Zhao, J. Qin, R. Rajagopal, A. Goldsmith, and H. V. Poor, "Wind aggregation via risky power markets," IEEE Trans. Power Syst., vol. 30, no. 3, pp. 1571-1581, May 2015

[9] N. Zhang, C. Kang, Q. Xia, Y. Ding, Y. Huang, R. Sun, J. Huang, and J. Bai, "A convex model of risk-based unit commitment for day-ahead market clearing considering wind power uncertainty," IEEE Trans. Power Syst., vol. 30, no. 3, pp. 1582-1592, May 2015.

[10] J. D. Lyon, F. Wang, K. W. Hedman, and M. Zhang, "Market implications and pricing of dynamic reserve policies for systems with renewables," IEEE Trans. Power Syst., vol. 30, no. 3, pp. 1593-1602, May 2015.

[11] F. J. de Sisternes, M. D. Webster, and I. J. Prez-Arriaga, "The impact of bidding rules on electricity markets with intermittent renewables," IEEE Trans. Power Syst., vol. 30, no. 3, pp. 1603-1613, May 2015.

[12] E. Moiseeva, M. R. Hesamzadeh, and D. R. Biggar, "Exercise of market power on ramp rate in wind-integrated power systems," IEEE Trans. Power Syst., vol. 30, no. 3, pp. 1614-1623, May 2015.

[13] B. Zhang, R. Johari, and R. Rajagopal, "Competition and coalition formation of renewable power producers," IEEE Trans. Power Syst., vol. 30, no. 3, pp. 1624-1632, May 2015.

[14] L. Maurovich-Horvat, T. K. Boomsma, and A. S. Siddiqui, "Transmission and wind investment in a deregulated electricity industry," IEEE Trans. Power Syst., vol. 30, no. 3, pp. 1633-1643, May 2015.

[15] T. Levin and A. Botterud, "Capacity adequacy and revenue sufficiency in electricity markets with wind power," IEEE Trans. Power Syst., vol. 30, no. 3, pp. 1644-1653, May 2015. 
Pierre Pinson (M'11-SM'13) received the M.Sc. degree in applied mathematics from the National Institute for Applied Sciences (INSA Toulouse, France) and the Ph.D. degree in energetics from Ecole des Mines de Paris (France).

He is a Professor at the Technical University of Denmark, Centre for Electric Power and Energy, Department of Electrical Engineering, also heading a group focusing on Energy Analytics \& Markets. His research interests include among others forecasting, uncertainty estimation, optimization under uncertainty, decision sciences, and renewable energies.

Prof. Pinson acts as an Editor for the IEEE TRANSACTIONS ON POWER SySTEMS, for the International Journal of Forecasting, and for Wind Energy.

Mark O'Malley (F'07) received the B.E. and Ph.D. degrees from University College Dublin, Dublin, Ireland, in 1983 and 1987, respectively.

He is a Professor of Electrical Engineering with University College Dublin, Dublin, Ireland, and Director of the Electricity Research Centre with research interests in power systems, grid integration of renewable energy, control theory, and biomedical engineering. 